\title{
Study of admission cardiotocography screening of high risk obstetric cases and its correlation with perinatal outcome
}

\author{
Thakur Archana ${ }^{1}$, Singh Kavita $\mathbf{N}^{2, *}$, Sahani Sonal ${ }^{3}$ \\ ${ }^{1}$ PG Student, ${ }^{2}$ Professor and HOD, ${ }^{3}$ Assistant Professor, Dept. of Obstetrics and Gynaecology, Netaji Subhash Chandra Bose \\ Medical College, Jabalpur, Madhya Pradesh, India
}

*Corresponding Author:

Email: dr_animeshgupta@ rediffmail.com

\begin{abstract}
Objective: To predict the neonatal outcome in high risk obstetric cases by performing admission cardiotocography (CTG) testing.

Aims: To study role of admission CTG in early detection of fetal hypoxia. To do correlation of admission CTG results and immediate perinatal outcome in high risk obstetric cases.

Materials and Methods: The study was conducted in department of Obstetrics \& Gynecology N.S.C.B. Medical College, Jabalpur from $1^{\text {st }}$ June 2009 to $31^{\text {st }}$ Oct. 2010. A total of 106 high risk cases meeting the inclusion criteria were subjected to admission CTG testing in this prospective study. Result of admission CTG testing was correlated with perinatal outcome.

Results: The admission test had sensitivity of $38.1 \%$, specificity of $100 \%$ and positive predictive value of $100 \%$ for predicting an Apgar score $<5$ at birth with diagnostic accuracy of $87.7 \%$. Neonatal admission to neonatal intensive care (NICU) was required in $76.2 \%$ of patients with an abnormal test result while only $36.5 \%$ of patients with the normal test results were subjected to NICU admission and this was statistically significant $\left(\chi^{2}=10.76 ; \mathrm{p}<0.01\right)$.

Conclusions: The results suggested that electronic fetal monitoring (CTG) is mandatory in all high risk obstetric cases on admission.
\end{abstract}

Keywords: CTG (cardiotocography), High risk cases, Perinatal outcome.

\section{Introduction}

In India infant mortality rate is 34 (IMR- per 1000 live birth). ${ }^{1}$ Most of the mortality risk is in first four weeks. As high as 15 times greater than any other time before first year. ${ }^{2}$ Obstetricians are concerned with the early recognition of fetal distress during the labour in order to avoid adverse outcome and neonatal mortality. Our surveillance system must detect compromised fetuses and ensure their safe delivery. The admission cardiotocography (CTG) test is a short continuous electronic FHR recording for a period of 20 minutes, along with simultaneous recording of uterine activity and patient heart rate done immediately on admission to the labour suite. Continuous NST monitoring helps in deciding time and mode of delivery.

\section{Aims}

1. To study role of admission CTG in early detection of fetal hypoxia.

2. To correlate admission CTG results with immediate perinatal outcome in high risk obstetrics cases.

\section{Materials and Methods}

Study Design: Prospective observational study Study Period: $1^{\text {st }}$ July 09 to $30^{\text {th }}$ August 10

Study Place: Department of Obstetrics \& Gynaecology, NSCB Medical College, Jabalpur.

Sample Size: 106 high risk obstetrics cases (simple random sampling)

\section{Inclusion Criteria:}

Gestational Age: More than 34 weeks of gestation.

Pregnancy with high risk factors: History of recurrent pregnancy loss, previous history of any stillbirth, pregnancy induced hypertension, anemia, diabetes mellitus, Rh negative, PROM, previous cesarean section, intrauterine growth restriction, postdatism, complain of diminished foetal movement

Ethical Clearance: Institutional ethics committee of N.S.C.B. Medical College Jabalpur (M.P.) India approved the study protocol.

\section{Method}

In present study 106 high risk obstetrics cases with inclusion criteria were subjected to CTG at the time of admission. The results of CGT test were categorized into reactive and nonreactive. In 5 cases where suspicious CTG was found, in those cases CTG was done for $\geq 90$ minutes and then the decision was taken according to Royal College of Obstetricians and Gynaecologist (RCOG) guideline for the interpretation of CTG tracings. ${ }^{3}$

RCOG criteria for interpretation of the admission test:

Criteria for the normal / reassuring trace:

a. At least 2 accelerations (>15bpm for $>15 \mathrm{sec})$ in 20 minutes

b. Base line heart rate- $110-160 \mathrm{bpm}$

c. Baseline variability- $5-15 \mathrm{bpm}$

d. Absence of decelerations

e. Moderate tachycardia- (161-180bpm) 
bradycardia- (100-109bpm) but with preservation of baseline variability and accelerations.

Criteria of suspicious/equivocal trace :

a. Reduced baseline variability- $(<5 \mathrm{bpm})$ for $>$ 40 minutes but $<90$ minutes although baseline heart rate normal- $(110-160 \mathrm{bpm})$.

b. Variable decelerations- (depth $<60 \mathrm{bpm}$ and duration $<60$ seconds)

c. Early decelerations

d. Single prolonged deceleration $<3$ minutes

Criteria of abnormal/pathological trace:

a. Silent base line variability- $(<5 \mathrm{bpm})$ pattern $>90$ minutes

b. Base line heart rate- $>180 \mathrm{bpm}$ or $<100 \mathrm{bpm}$.

c. Late deceleration

d. Atypical/significant variable decelerations(depth $>60 \mathrm{bpm}$ and duration $>60 \mathrm{sec}$ )

e. Prolonged bradycardia (drop of the foetal heart rate $<100 \mathrm{bpm}$ for $>3$ minutes or $<80 \mathrm{bpm}$ for $>2$ minutes)

f. Sinusoidal patterns $>10$ minutes

\section{Results}

Out of 106 cases $85(80.2 \%)$ had a reactive and 19 $(19.8 \%)$ had a non-reactive NST. In present study most common indications for non stress test were PIH 26(24.52\%), previous section 25(23.58\%), PROM/ Oligo 15 (14.15\%), decrees fetal movement 15 (14.11\%), anemia $13(12.26 \%)$, post datism $10(9.43 \%)$, IUGR 7 (6.6\%), diabetes1 (0.9\%) and Bad obstetrics history $1(0.9 \%)$. Reactive NST (Fig. 1) shows a normal CTG. Presence of accelerations usually associated with fetal movements and appears to suggest an intact somatic nervous system. ${ }^{4}$ Early deceleration pattern (Fig. 2) and variable deceleration (Fig. 4) are a suspicious finding and should not be missed. Oligohydramnios is a cause of variable decelerations and a in Cochrane review on amniofusion for potential or suspected umbilical cord compression during labor concluded that amniofusion is useful to reduce the variable decelerations and to reduce the cesarean section mainly for fetal distress diagnosed by fetal heart rate monitoring alone. ${ }^{5}$ Non reactive NST has different pattern- Late deceleration (Fig. 3) and sinusoidal pattern (Fig. 5). Non reactive + NST had definite role in prediction of following parameters of the perinatal outcome as low apgar score at 1 and 5 minute after birth, presence of meconium aspiration, neonatal intensive care (NICU) admission and neonatal mortality (Table 1 and Table 2). There was statistically significant ( $\mathrm{P}$ value <0.001) correlation between nonreactive NST and apgar score at 1 minute after birth. With abnormal admission test 8 neonate were found to have low apgar score at 5 mins after birth. This low apgar score was due to meconium aspiration, hypoxic ischemic encephalopathy (HIE) and Respiratory distress syndrome (RDS). In 5 neonates cause of mortality was associated with high risk pregnancy i.e. pregnancy induced Hypertension, ${ }^{2}$ severe anemia, ${ }^{2}$ and abruption placentae. ${ }^{1}$ Non reactive NST was found in $46.7 \%$ of PIH patients and early detection by NST can improve perinatal outcomes (Table 3) There was statistically significant difference in the reactivity of NST with cases presented with the decreased fetal movement $(\mathrm{P}<0.05)$. (Table 4) 21 non reactive cases $10(47 \%)$ had undergone LSCS and $11(53 \%)$ had undergone normal vaginal delivery (Table 5). So, NST does not carry the unnecessary increased risk of intervention.

Table 1: Correlation of perinatal outcome with the admission test

\begin{tabular}{|l|c|c|c|}
\hline & Non reactive & Reactive & P value \\
\hline Apgar score 1 minutes after birth between 0-4 & $21(100 \%)$ & $19(22.4 \%)$ & $<0.001$ \\
\hline Apgar score 5min after birth between 0-4 & $8(38.1 \%)$ & $0(0 \%)$ & $<0.01$ \\
\hline Presence of meconium & $14(66.7 \%)$ & $5(5.9 \%)$ & $<0.0001$ \\
\hline Admission to NICU & $16(76.2 \%)$ & $31(36.5 \%)$ & $<0.01$ \\
\hline Intrapartum/Neonatal mortality & $5(23.8 \%)$ & $0(0 \%)$ & $<0.001$ \\
\hline
\end{tabular}

* NST had definite role in prediction of parameters of perinatal outcome.

Table 2: Statistical significance of various parameters of perinatal outcome

\begin{tabular}{|l|c|c|c|c|c|}
\hline \multicolumn{1}{|c|}{ Outcome } & Sensitivity & Specificity & $\begin{array}{c}\text { Positive } \\
\text { predictive value }\end{array}$ & $\begin{array}{c}\text { Negative } \\
\text { predictive } \\
\text { value }\end{array}$ & $\begin{array}{c}\text { Diagnostic } \\
\text { Accuracy }\end{array}$ \\
\hline Apgar score<6 at $1 \mathrm{~min}$ & $100 \%$ & $76 \%$ & $52.5 \%$ & $100 \%$ & $82 \%$ \\
\hline $\begin{array}{l}\text { Apgar score <7 at 5 min } \\
\text { after birth }\end{array}$ & $38.1 \%$ & $100.0 \%$ & $100.0 \%$ & $86.7 \%$ & $87.7 \%$ \\
\hline Admission to NICU & $76.2 \%$ & $63.5 \%$ & $34.01 \%$ & $91.5 \%$ & $66.0 \%$ \\
\hline Presence of meconium & $90.5 \%$ & $100 \%$ & $100 \%$ & $97.7 \%$ & $98.1 \%$ \\
\hline Perinatal mortality & $23.8 \%$ & $100 \%$ & $100 \%$ & $84.2 \%$ & $84.9 \%$ \\
\hline
\end{tabular}


Table 3: Correlation of reactivity of NST with PIH group

\begin{tabular}{|l|c|c|}
\hline \multirow{2}{*}{ Indications } & \multicolumn{2}{|c|}{ Cardiotocography } \\
\cline { 2 - 3 } & Reactive & Non- reactive \\
\hline PIH & $14(53.8)$ & $12(46.2 \%)$ \\
\hline Others & $71(88.8 \%)$ & $9(11.3 \%)$ \\
\hline Total & 85 & 21 \\
\hline
\end{tabular}

$* \chi 2=15.05, \mathrm{P}<0.0001$
Table 4: Correlation of reactivity of NST with decrease fetal movement

\begin{tabular}{|c|c|c|}
\hline \multirow[t]{2}{*}{ Indications } & \multicolumn{2}{|c|}{ Cardiotocography } \\
\hline & Reactive & Non- reactive \\
\hline $\begin{array}{l}\text { Cases with } \\
\text { decreased FM }\end{array}$ & $9(60 \%)$ & $6(40 \%)$ \\
\hline Normal FM & $76(83.5 \%)$ & $15(16.5 \%)$ \\
\hline
\end{tabular}

Table 5: Correlation between reactivity of NST and mode of delivery

\begin{tabular}{|l|c|c|c|}
\hline \multicolumn{1}{|c|}{ Mode of delivery } & Non-reactive & Reactive & Total \\
\hline LSCS & $10(15.9 \%)$ & $53(84.1 \%)$ & $63(100 \%)$ \\
\hline NVD & $11(25.6 \%)$ & $32(74.4 \%)$ & $43(100 \%)$ \\
\hline & 21 & 85 & 106 \\
\hline
\end{tabular}

$* \chi^{2}=1.52, \mathrm{P}>0.05$

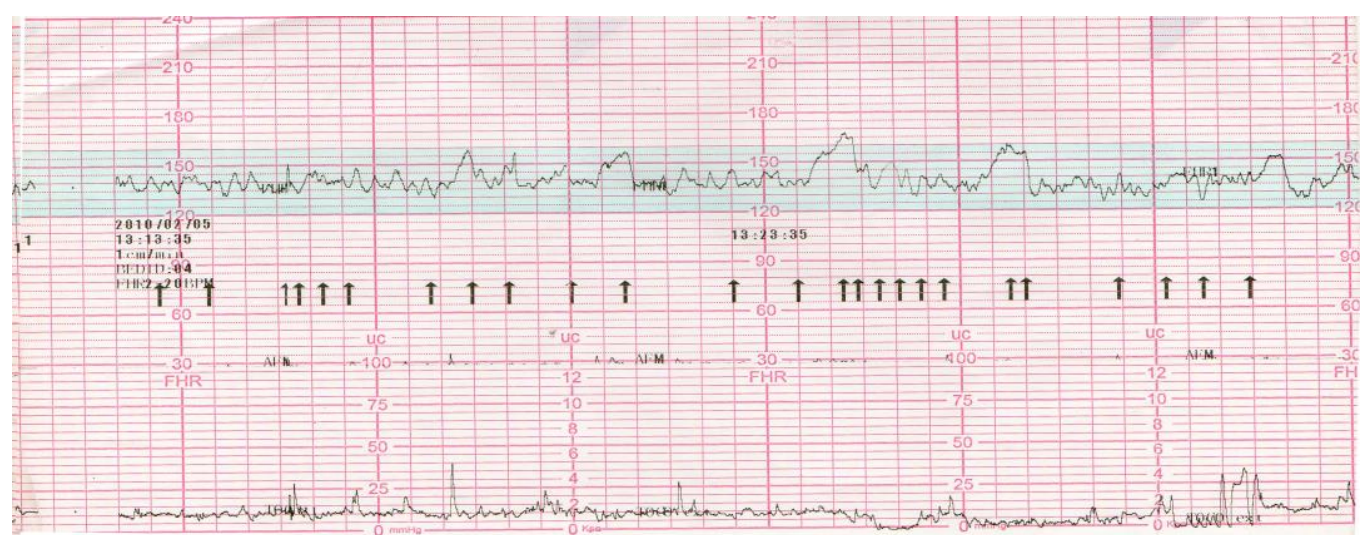

\section{Normal CTG}

Fig. 1:

Normal CTG -3 accelerations of more than 15 beats in 20 minutes

Baseline variability is 10 to 15

Baseline fetal Heart rate -134/minute

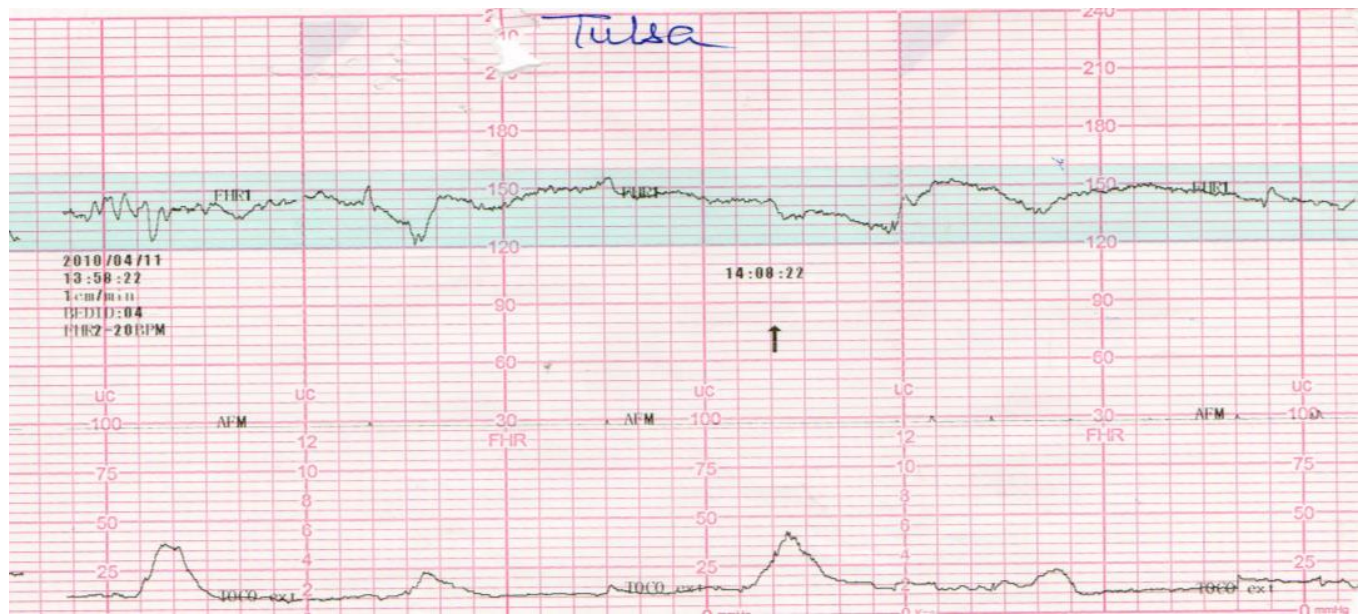

Early Deceleration

Fig. 2:

* Early deceleration -Also known as mirror image decelerations

2 deceleration present immediately after contractions.

Signifies head compressions with uterine contractions 


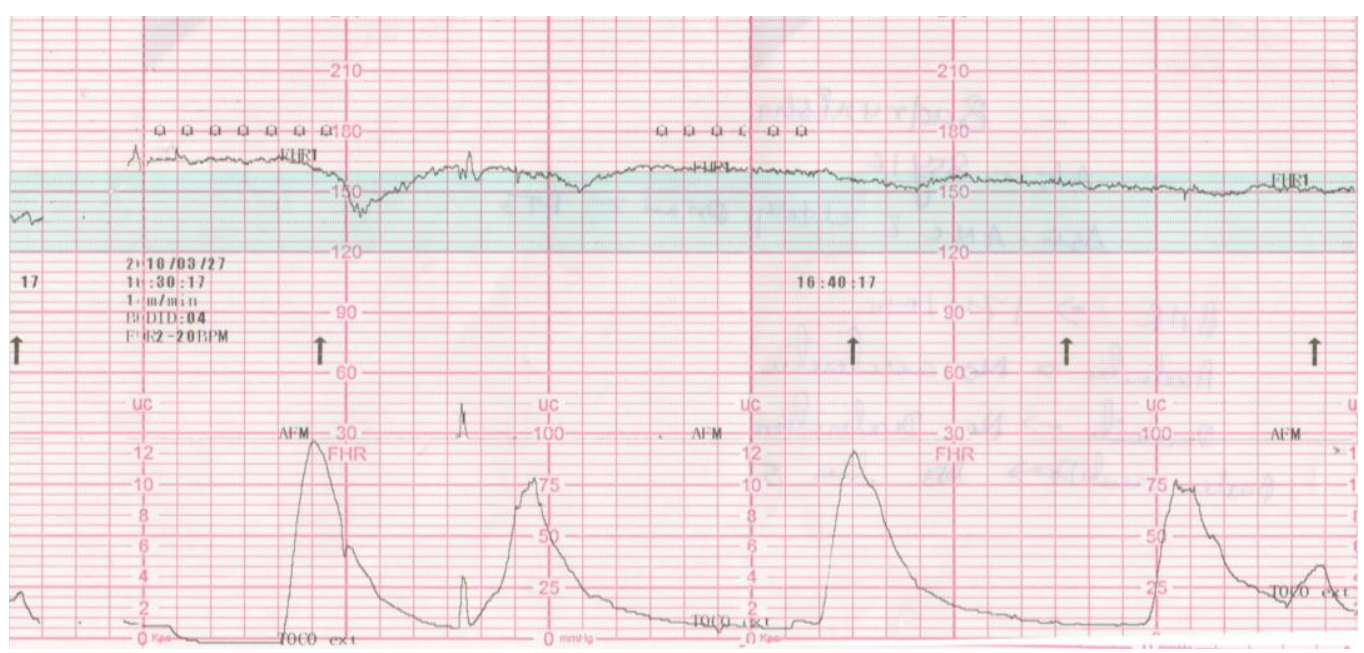

\section{Late Deceleration}

Fig. 3:

* Late deceleration - signifies fetal hypoxia

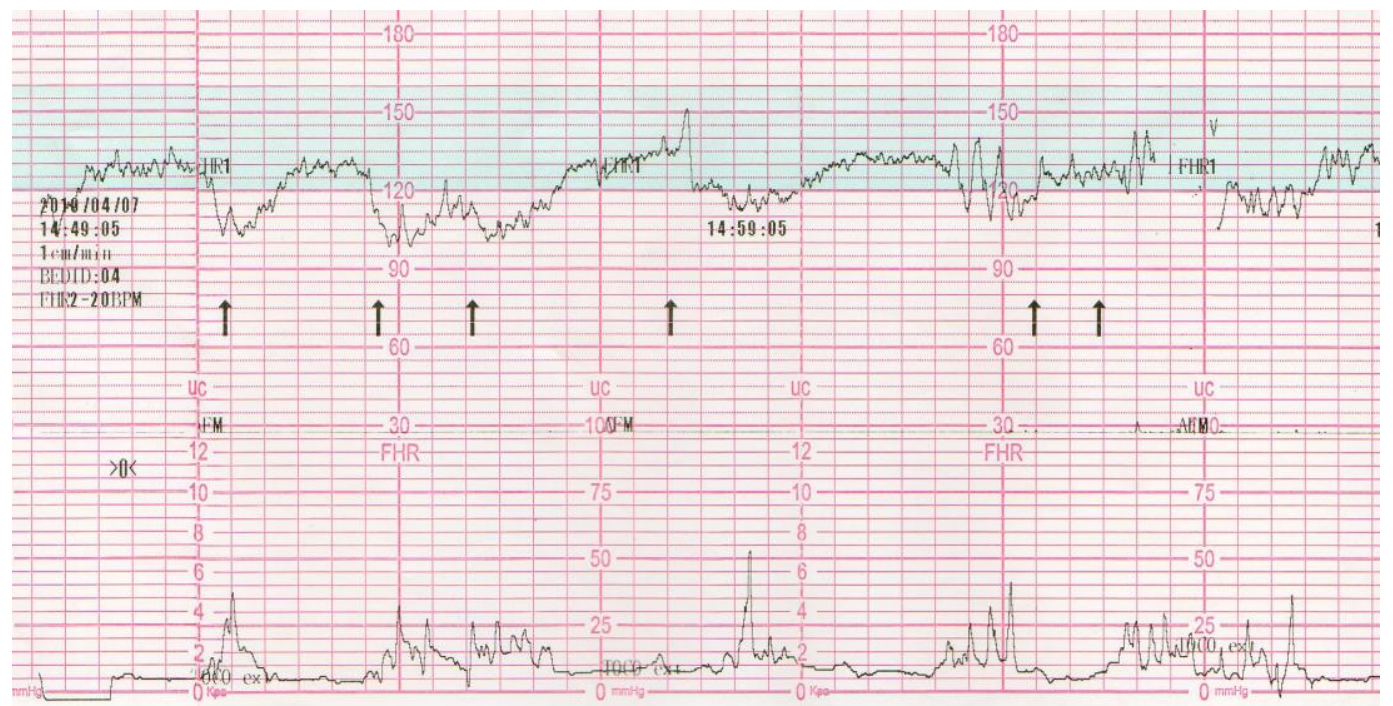

\section{Variable Deceleration}

Fig. 4:

* Variable deceleration - signifies cord compression 


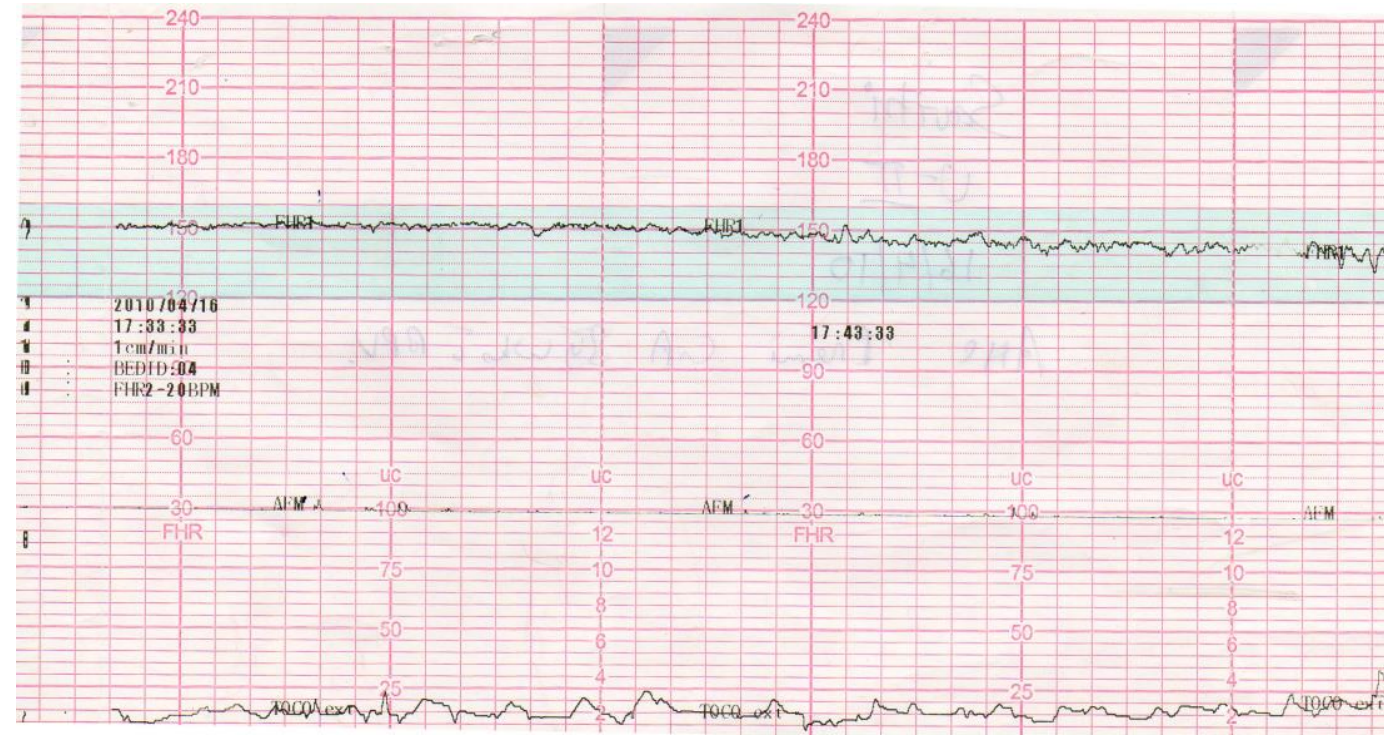

Sinosoidal Pattern

Fig. 5:

Sinosoidal pattern - Beat to beat variablity is less than 5

Seen in $\mathrm{Rh}$ incompatibility and severe iron deficiency anemia

\section{Discussion}

The admission test first described by Ingemarsson et al is a short strip of contraction during the labour. ${ }^{6}$ It is a dynamic screening test for state of oxygenation of fetus at admission of the mother to labour room. It can be used as a screening test in early labour to detect women in need of continuous fetal electronic monitoring during labour. ${ }^{7}$ The neonatal admission to NICU was necessitated in $36.5 \%$ of the patients with a normal test and in $76.2 \%$ of patients with abnormal test. The Cochrane review recommend that continuous electronic fetal monitoring be limited to the high risk pregnancies. ${ }^{8}$ Fetal pulse oximetry (FSpO2) above 30 $\%$ is associated with a good fetal outcome. CTG correlates well with the FSpO2 and enables a direct and continuous assessment of fetal oxygenation. Its drawbacks include technical difficulties in placing the device in the presence of a high presenting part and inability to get continuous reading due to contact sensor. ${ }^{9}$ Our study support a role for admission testing in the high risk population. A reassuring CTG tracing at admission to the delivery suit is a reliable indicator of fetal well being. Entire clinical picture should be considered, while reading and interpreting CTG. These include stage and progress of the labor, ability of the fetus to withstand further hypoxia, uterine activity, oxytocin augmentation and feasibility of assisted vaginal delivery. If an abnormality is noted, intervention does not always warrant immediate delivery. Simple measures such as hydration, changing maternal position, reduction or temporarily stopping oxytocin infusion and rarely acute tocolysis may help to restore the CTG trace back to normal. ${ }^{10}$

\section{Conclusion}

Non stress test is a noninvasive and good screening test to evaluate the fetal health and to predict perinatal outcome. In high risk pregnancies after 34 weeks of gestation screening test is a very useful test in prediction of fetal hypoxia thereby helping obstetrician in decision making for induction of labour/to wait for spontaneous onset of labour. Clinical decision should be taken on basis of modified biophysical profile. In our study out of 21 non reactive cases $10(47 \%)$ had undergone LSCS and 11 (53\%) had undergone normal vaginal delivery. So, NST does not carry the unnecessary increased risk of intervention. NST is simple, easily performed, interpreted by obstetrician and readily accepted by the patients.

\section{Acknowledgements}

I would like to express my special thanks of gratitude to my teacher Dr. Kavita N Singh and Dr. Sonal Sahani who gave me golden opportunity to do this study. I came to know so many new things.

Secondly I would like to thank my parents and friends.

Funding: NSCB medical college Jabalpur M.P

\section{Conflict of Interest: None}

\section{Reference}

1. www.niti.gov.in/content/infant-mortality-rate-imr-1000live-birth

2. www.who.int/pmnch/media/press_materials/fs/fs_newbor ndealth_illness/en

3. RCOG Evidence based Clinical Guideline number 8 . The use of electronic fetal monitoring: The use and 
interpretation of cardiotocography in intrapartum fetal surveillance. London: RCOG press, 2001;52.

4. Chandraharan Edwin, Sabaratnam Arulkumarn, Review Article-Electronic fetal heart rate monitoring in current and future practice J Obstet Gynecol India Vol. 58, No. 2: March/April 2008 p.121-130.

5. Hofmeyr GJ. Amnioinfusion for potential or suspected umbilical cord compression in labor. Cochrane Database Syst Rev 2000;3:CD000013.

6. Inggemarsson I, Arulkumaran S, Ingemarsson E, Tambyraja RL, Ratnam SS. Admission test: A screening test for fetal distress in labour. Obstet \& Gynecol 1986;68:800-6.

7. Blix E, Reinar LM, Klovning A, Oian P, Prognostic value of the labour admission test and its effectiveness compared with auscultation only: A systematic review. Br. J Ostet Gynaecol 2005:112:1595-1604.

8. Thacker SB, Stroup D, Chang M, Continuous electronic heart rate monitoring for fetal assessment during labour (Cochrane Review). In the Cochrane Library, issue 4, 2001. Oxford: Update Software.

9. Dildy GA. Fetal pulse oximetry: a critical appraisal. Best Pract Res Clin Obstet Gynaecol 2004;18:477- 84.

10. Williams B, Arulkumaran S. Cardiotocography and medicolegal issues. Best Pract Res Clin Obstet Gynaecol 2004;18:457-66. 